\title{
Paracetamol and Asthma: is the evidence is robust enough to change the guidelines: an overview of systematic reviews
}

\author{
Suresh Varukolu ${ }^{1}$, Manvi Singh ${ }^{2}$, Anil Chauhan ${ }^{3}$, Nishant Jaiswal ${ }^{3}$, Pranita Pradhan ${ }^{2}$, and \\ Meenu Singh ${ }^{2}$ \\ ${ }^{1}$ Smartanalyst India Pvt Ltd \\ ${ }^{2}$ Postgraduate Institute of Medical Education and Research \\ ${ }^{3}$ Post Graduate Institute of Medical Education and Research
}

November 10, 2020

\begin{abstract}
Objective: To conduct an umbrella review collating the existing evidence to determine whether there is an association between exposure of paracetamol in utero or in infancy, and the development of childhood asthma. Methods: In this review, systematic reviews with or without meta-analysis that reported the association between paracetamol and asthma in children were included. To identify relevant reviews, a search was performed in the electronic databases PubMed, the Cochrane Central Register of Controlled Trials Library, and Ovid. Results: The search strategy in various databases identified 1913 conceivably significant studies for inclusion. After removal of 493 duplicates ,1420 studies were screened for titles and abstracts against a standard eligibility criterion. Full text screening yielded four systematic reviews to be included in this review. Prenatal paracetamol exposure is associated with an increased risk of Asthma in the offspring. Of the four systematic reviews, 2 have an unclear risk of bias, one has a high risk and one has a low risk of bias. Association does not imply causation and we recommend further research to answer this very important question. In the absence of any other alternative, paracetamol will have to continue to be the safest and the most widely prescribed analgesic and antipyretic in pregnancy. Conclusions: We recommend further research to answer this very important question. In the absence of any other alternative, paracetamol will have to continue to be the safest and the most widely prescribed analgesic and antipyretic in pregnancy.
\end{abstract}

\section{Hosted file}

PCM.pdf available at https://authorea.com/users/366833/articles/492095-paracetamoland-asthma-is-the-evidence-is-robust-enough-to-change-the-guidelines-an-overview-ofsystematic-reviews

\section{Hosted file}

Table 1.pdf available at https://authorea.com/users/366833/articles/492095-paracetamoland-asthma-is-the-evidence-is-robust-enough-to-change-the-guidelines-an-overview-ofsystematic-reviews

\section{Hosted file}

Table 2.pdf available at https://authorea.com/users/366833/articles/492095-paracetamoland-asthma-is-the-evidence-is-robust-enough-to-change-the-guidelines-an-overview-ofsystematic-reviews

\section{Hosted file}


Figure 1.pdf available at https://authorea.com/users/366833/articles/492095-paracetamoland-asthma-is-the-evidence-is-robust-enough-to-change-the-guidelines-an-overview-ofsystematic-reviews 